\title{
Editorial
}

\section{ENTRE LA EDUCACIÓN EN TIEMPOS DE PANDEMIA DE HOY Y LA CULTURA INCLUSIVA DE MAÑANA}

\author{
Dra. C. Xiomara Sánchez Valdés
}

Licenciada en Educación Especial. Máster en Ciencias de la Educación, mención Educación Especial. Doctora en Ciencias Pedagógicas. Profesora titular del departamento Educación Especial de la Facultad de Educación Infantil de la Universidad de Pinar del Río "Hermanos Saíz Montes de Oca". Cuba ORCID ID: https://orcid.org/0000-0002-4518-2333 Email: xiomara.sanchez@upr.edu.cu

Ha pasado poco más de un año, desde que la Organización Mundial de la Salud declarara, el 30 de enero de 2020, la COVID-19 como emergencia internacional de salud pública y se convirtiera, en fecha temprana del 11 de marzo de 2020, en estado de pandemia (OPS, 2020). La amenaza, el riesgo y el estado de vulnerabilidad alcanzaron a todos por igual, sin distinción de clase social, raza, etnia, género y capacidades, entre otros aspectos. La humanidad, en toda su diversidad, se vio afectada.

Aun así, los mecanismos de enfrentamiento no se desplegaron en todos los países por igual, dada una compleja trama de causas histórico-sociales. La Comisión Económica para América Latina y el Caribe (CEPAL) identificó el deterioro de las condiciones sociales, de salud, educacionales, los altos índices de pobreza (en ocasiones extrema), las desigualdades, la violencia de género, las fragilidades ante las situaciones de discapacidad, alimentación, las posibilidades de los sectores indígenas, que ya enfrentaba la sociedad en la etapa pre-pandemia (CEPAL-UNESCO, 2020).

De formas disímiles, todos los sectores de la sociedad se vieron afectados. La educación en su plena lucha por ser inclusiva, no fue la excepción ante la COVID-19, enfrentó un impacto que vino a interrumpir progresos, reabrir heridas y profundizar males en el campo educacional.

Con anterioridad, ya se habían consignado los Objetivos de Desarrollo Sostenible con sus respectivas Metas en la Agenda 2030, como «una herramienta de planificación para los países, tanto a nivel nacional como local», a tenor de poner «la dignidad y la inclusión de las personas en el centro» (Naciones Unidas, 2016, p.5). La propuesta signada por 193 Estados Miembros, mantiene su vigencia y constituye un elemento conciliador ante la situación actual. 
Durante este año, las acciones de enfrentamiento, de contención, de protección de la salud han impregnado y dirigido la educación, revitalizando su papel en la sociedad. «La pandemia de COVID-19 exacerbó las desigualdades sociales, la inequidad y la exclusión, al tiempo que se transformó paradójicamente en una oportunidad para el fortalecimiento de las relaciones sociales, guiadas por los sentimientos de solidaridad y colaboración en torno a la búsqueda del bien común, y también por la responsabilidad por el cuidado del otro, como una dimensión esencial delcuidado y supervivencia de uno mismo» (CEPAL-UNESCO, 2020, p.16).

Esta nueva otredad puede constituir una fuerza de transformación, liberadora para muchos. No es objetivo de este artículo sistematizar los efectos de la pandemia en la educación durante este año de enfrentamiento, sino reflexionar sobre la savia del embate que se está enfrentando, con el propósito que el presente que se está viviendo catalice los cambios que generen una cultura más inclusiva mañana.

Tampoco se trata de un diálogo utópico, sino optimista, al valorar algunos de los aciertos en el enfrentamiento a la pandemia. Se abraza la idea de Freire (2010): «Es preciso no trasmitir la idea que cambiar es fácil; cambiar es difícil pero posible. Debemos insistir sobre la posibilidad de cambiar, a pesar de las dificultades» (p.157).

Una invitación a la colaboración la ofrece la Unesco en su informe de Educación en el Mundo 2020América Latina y el Caribe- Inclusión y educación: todas y todos, sin excepción al reconocer importantes ejemplos de núcleos de inclusión educativa en la región, que pueden servir de referencia en el valor de la diversidad y hace un llamado a «ponerse manos a la obra y trabajar en esa dirección, luchando activamente contra la persistencia de la discriminación y la segregación»(UNESCO, 2020, p.v).

Pensando en la cultura, sin intentar definirla, se comparte la idea intuitiva de que es un atributo exclusivo de la humanidad que a diferencia del resto de las especies ofrece la «capacidad para elaborar ideas sobre el mundo y sobre nosotros mismos y trasmitirlas a las generaciones siguientes, cambiando permanentemente el punto de partida de cada generación» (Lage, 2018, p.215). Ante esta posición, la crisis de hoy puede ser un punto de inflexión hacia un futuro enriquecido por la diversidad para todos y todas.

En los entornos educativos, la cultura constituye una dimensión esencial, estrechamente vinculada a las políticas y las prácticas inclusivas. «Las Culturas reflejan las relaciones, los valores y las creencias profundamente arraigadas en su comunidad educativa. Cambiar las culturas es esencial a fin de sustentar la mejora» (Booth y Ainscow, 2011, p.17).

Al igual que la savia, invisible desde afuera, pero que constituye energía y nutrición vital para las plantas, se resaltan enseñanzas necesarias a nivel de comunidad escolar, que ahora ha perdido sus límites 
y se infiltra al hospital, la comuna, la vecindad, el hogar, el cuarto. La escuela extramuros es protagonista del desarrollo de hábitos higiénicos precisos, del cumplimiento de las medidas de sanidad y de estrechar los vínculos con la familia y la comunidad.

La CEPAL-UNESCO (2020) sugiere, entre otros, que se prioricen las competencias y los valores revelados en la actual coyuntura como pueden ser la solidaridad, el aprendizaje autónomo, el cuidado propio y de otros, las competencias socioemocionales, la salud y la resiliencia.

En términos curriculares, se ha aprendido que la integración de temas en diferentes asignaturas, desde una visión más holística y transdisciplinaria es posible, mediante metodologías de proyectos o investigaciones que permitan un abordaje integrado de los aprendizajes y formas novedosas de evaluación.

También se ha visibilizado la necesidad de priorizar la reflexión, el pensamiento crítico, la comprensión de las dinámicas sociales y económicas, la literacidad informativa en torno al bombardeo mediático, las fakenews y el uso de las redes sociales.

El período vivido ha mostrado ejemplos de búsqueda de alternativas ante las brechas de acceso al mundo digital, con el empleo de teleclases, repasadores en línea, orientaciones a la familia, grupos de autoayuda por teléfono, gratuidades en el acceso a sitios digitales escolares, reaperturas de ciclos docentes de forma escalonada, entre otras experiencias válidas a ser tomadas en cuenta (MINED-UNICEF, 2020).

Los obstáculos que se han enfrentado han retado la creatividad humana, toda vez que se hace un llamado a estrechar los lazos entre ciencia, tecnología e innovación al servicio de la sociedad. Los docentes en particular se han visto desafiados a expresar soluciones innovadoras y estrechar la comunicación con estudiantes y familiares (Duk y Murillo, 2021).

Si bien es cierto que las familias han enfrentado situaciones complejas, también lo es que muchas han ganado confianza y participación en el proceso educativo de sus hijos y en el de cada miembro en particular, como parte del aprendizaje durante toda la vida.

El aprendizaje socioemocional, también emerge, no solo como apoyos individuales y contingentes, sino tal y como sugiere la (CEPAL-UNESCO, 2020, p.14) como «un proceso de aprendizaje permanente, tanto en los períodos de confinamiento y educación a distancia como en el plan de retorno escolar". Los mecanismos de compensación socioemocionales de hoy, pueden ser sustrato de mejores relaciones humanas, sobre la base de un mejor conocimiento de sí mismo en diferentes circunstancias. 
Los análisis realizados hasta la fecha, la determinación de los aciertos y desaciertos, las circunstancias y las lecciones aprendidas, constituyen el colofón para situar la educación, en toda su dimensión, como principal gestora de la sostenibilidad en el planeta, el respeto a la diversidad, la convivencia pacífica y enriquecedora de todas y todos, sin excepción. Para ello necesitamos, entre otras cosas, pensamiento crítico, científico y transformador, que libere y despeje al egoísmo, el neoliberalismo y el irrespeto a la identidad. En este camino que promueve la cultura inclusiva del mañana, germina la idea del pedagogo y filósofo Freire (2010): «(...) La cuestión está en cómo transformar las dificultades en posibilidades. Por esto, en la lucha por cambiar, no podemos ser ni sólo pacientes ni sólo impacientes, sino pacientemente impacientes» (p.157).

\section{Referencias consultadas}

UNESCO. (2020). Informe de Seguimiento de la Educación en el Mundo 2020 - América Latina y el Caribe - Inclusión y educación: todos y todas sin excepción. París, UNESCO. Recuperado de: https://www.google.com/url?sa=t\&source=web\&rct=j\&url=https://reliefweb.int/report/world/informe-de-seguimiento-de-la-educaci-nen-el-mundo-2020-inclusi-n-y-educaci-n-todos-y\&ved=2ahUKEwj2zouovP7vAhULZd8KHVCMCrUQFjAAegQIAxAC\&usg=AOvVaw1qBd6B3eHtpn6UnQn6WCON

Ministerio de Educación de la República de Cuba (MINED) y Fondo Mundial para la Infancia (UNICEF).(2020). Educación en tiempos de covid-19. La experiencia cubana. UNICEF. Recuperado de: https://www.unicef.org/lac/ media/21176/file\&ved=2ahUKEwi06Y6v4v7vAhXDUt8KHdfPBYYQFjAAegQIAxAC\&usg=AOvVaw2UugDLpVQQp3APovQTyUkt

Duk, C., y Murillo, F.J. (2021). El Derecho a la Educación es el Derecho a una Educación Inclusiva y Equitativa. Revista Latinoamericana de Educación Inclusiva, 2020, 14(2), 11-13 DOI: http://dx.doi.org/10.4067/S071873782020000200011

CEPAL-UNESCO. (2020). Informe covid-19. La educación en tiempo de la pandemia de covid-19. Recuperado de: https://www.google.com/url?sa=t\&source=web\&rct=j\&url=https://www.cepal.org/es/publicaciones/45904-la-educacion-tiempos

OPS (2020). Enfermedad por el coronavirus (COVID-19). Recuperado de https://www.paho.org/es/enfermedad-por-coronavirus-covid-19

Naciones Unidas. (2016). La Agenda 2030 y los Objetivos de Desarrollo Sostenible: una oportunidad para América Latina y el Caribe. Objetivos, metas e indicadores mundiales. Recuperado de: https://www.google.com/url?sa=t\&source=web\&rct=j\&url=https://repositorio.cepal.org/bitstream/handle/11362/40155/20

Freire, P. (2010). Pedagogía de la autonomía y otros textos, «A la sombra de este mango», Editorial Caminos: La Habana. 